\title{
WestVirginiaUniversity
}

THE RESEARCH REPOSITORY @ WVU

Graduate Theses, Dissertations, and Problem Reports

1999

\section{Back to nature to beat the blues}

Shannon Leigh Kirby Lawson
West Virginia University

Follow this and additional works at: https://researchrepository.wvu.edu/etd

\section{Recommended Citation}

Lawson, Shannon Leigh Kirby, "Back to nature to beat the blues" (1999). Graduate Theses, Dissertations, and Problem Reports. 1029.

https://researchrepository.wvu.edu/etd/1029

This Thesis is protected by copyright and/or related rights. It has been brought to you by the The Research Repository @ WVU with permission from the rights-holder(s). You are free to use this Thesis in any way that is permitted by the copyright and related rights legislation that applies to your use. For other uses you must obtain permission from the rights-holder(s) directly, unless additional rights are indicated by a Creative Commons license in the record and/ or on the work itself. This Thesis has been accepted for inclusion in WVU Graduate Theses, Dissertations, and Problem Reports collection by an authorized administrator of The Research Repository @ WVU. For more information, please contact researchrepository@mail.wvu.edu. 
Back to Nature to Beat the Blues

Shannon Kirby Lawson

\author{
Thesis submitted to the \\ School of Medicine \\ at West Virginia University \\ in partial fulfillment of the requirements \\ for the degree of \\ Master of Science \\ in \\ Community Health Promotion \\ Irene Tessaro, Ph.D., Chair \\ Rick Briggs, Ed.D. \\ R. Turner Goins, Ph.D. \\ Kenard McPherson, Ed.D. \\ Department of Community Medicine
}

Morgantown, West Virginia

1999

Keywords: Pet therapy, Social Support, Social Interaction, Nursing Home Residents

Copyright 1999, Shannon Kirby Lawson 


\section{Abstract \\ Back to Nature to Beat the Blues}

\section{Shannon Kirby Lawson}

The purpose of this study was to demonstrate a reduction in depressive symptoms in nursing home residents by using a pet therapy intervention to increase levels of social support and social interaction within the nursing home facility.

The target population in this study consisted of two nursing home facilities in West Virginia. Approximately 21 subjects participated in the study. An intervention using pet therapy was conducted in the intervention facility in which certified therapy animals "visited" the residents once a week for four weeks. The control group received a delayed intervention of gospel singing once a week for four weeks after posttest.

Data collection involved two techniques: a personal interview assessing the prevalence of depressive symptoms using the CES-D and the extent of the resident's social support, and natural observation during the pet therapy visits.

Analytical findings using a paired samples t-test show a significant increase in depressive symptoms in the intervention group at posttest and a significant decrease in depressive symptoms in the control group at posttest. Findings using a one way ANOVA show no significant difference in the rate that intervention subjects were seeking social support or social interaction between pretest and posttest. Observational findings show a consistent increase in positive reactions to the visits with the pets and interaction with the owners during the intervention period.

Contradictory findings from the quantitative and qualitative components of this study suggest further research could be used to determine whether pet therapy is, in fact, effective in decreasing depressive symptoms. 


\section{Acknowledgements}

I would like to express much appreciation to the members of my thesis committee, Dr. Irene Tessaro, Dr. R. Turner Goins, Dr. Rick Briggs, and Dr. Kenard McPherson for their guidance and patience through each phase of this study. Their enthusiasm for the project and expertise on the subject have been invaluable.

I would also like to thank Desiree Romanowski and Edward Cole for their assistance in data collection. But, most of all, I thank them for helping me keep my sense of humor.

Much appreciation goes to the nursing home facilities that opened their doors to this project and those subjects who agreed to be interviewed. Their hospitality and cooperation made the study more efficient and even more enjoyable.

A special thank you goes out to the volunteer owners and their wonderful therapy dogs, particularly Jere Craig for his expertise and assistance in organizing the visits. Without the donation of their time, effort, and willingness to share their extraordinary pets, the study would not have been possible.

Finally, I would like to thank my family for their continued support and encouragement during this project and before it began. I must also add a special thank you to my husband and baby for keeping me motivated and on track throughout. The combination of help from all of these special people has made completion of this project possible. 


\section{Table of Contents}

LIST OF TABLES viii

I. INTRODUCTION 1

A. Statement of Research Problem 1

B. Growth of At-Risk Population 1

C. WV Nursing Homes 2

D. Significance of the Proposed Work 2

E. Study Objectives $\quad 4$

F. Research Questions and Hypotheses 4

II. LITERATURE REVIEW

A. Depression in the Elderly 6

1. Treatments for Depression $\quad 7$

B. CES-D Depression Scale 8

C. Theoretical Framework 9

1. Animal Therapy and Social Support 10

III. RESEARCH METHODS 12

$\begin{array}{ll}\text { A. Study Population } & 12\end{array}$

B. Study Sample $\quad 14$

$\begin{array}{ll}\text { C. Research Design } & 14\end{array}$

D. Description of the Intervention 14

$\begin{array}{ll}\text { E. Data Collection Procedures } & 15\end{array}$

1. Personal Interview 15

2. Natural Observation 16 
$\begin{array}{ll}\text { F. Evaluation } & 17\end{array}$

$\begin{array}{ll}\text { G. Process Measures } & 18\end{array}$

$\begin{array}{ll}\text { H. Data Analysis } & 20\end{array}$

III. RESULTS

$\begin{array}{ll}\text { A. Observational Findings } & 21\end{array}$

1. Pet Therapy Visits 21

2. Record of Activities 25

B. Analytical Findings 26

1. Sample Characteristics 26

C. Baseline CES-D Scores 28

D. Communication Variables at Baseline 29

1. Intervention Communication $\quad 30$

2. Control Communication 30

E. Differences Between Groups 30

1. Intervention and Control CES-D Differences 30

2. Intervention and Control Interaction Differences 31

F. Main Findings $\quad 31$

1. Hypothesis One 31

2. Hypothesis Two 33

$\begin{array}{ll}\text { V. DISCUSSION } & 35\end{array}$

A. Study Limitations $\quad 35$

B. Summary of Major Findings 35

1. Hypothesis One 35 
2. Hypothesis Two 37

C. Implications of the Findings 42

D. Recommended Changes 43 


\section{APPENDICES}

A. Intervention and Control Group Pretest Questionnaire

B. Intervention Group Posttest Questionnaire

C. Control Group Posttest Questionnaire

53

D. Intervention Group Consent Form

E. Control Group Proposal

F. Intervention Group Proposal

62

G. Control Group Proposal 


\section{List of Tables}

$\begin{array}{lll}\text { Table } 1 & \text { Pet Therapy Visit } 1 & 22\end{array}$

$\begin{array}{lll}\text { Table } 2 & \text { Pet Therapy Visit } 2 & 23\end{array}$

Table $3 \quad$ Pet Therapy Visit 323

Table 4 Pet Therapy Visit $4 \quad 24$

Table 5 Resident Attendance to Weekly Activities 25

Table 6 Intervention Sample Demographics 27

Table 7 Control Sample Demographics 28

Table $8 \quad$ Median Response for Communication at Pretest 29

Table $9 \quad$ ANOVA at Pretest Between Groups for Communication 31

Table $10 \quad$ Mean CES-D Scores and T-Values Within Groups 32

Table 11 ANOVA Across Tests Within Intervention for Communication 33

Table 12 ANOVA at Posttest Between Groups for Communication 34 


\section{Introduction}

\section{$\underline{\text { Statement of the Research Problem }}$}

Within the next thirty years, the number of elderly in the United States is expected to double (AoA Profile of Older Americans, 1998). This rise in the elderly population will affect West Virginia as well as the nation as a whole. In order to prepare for this growth, health care professionals must be aware of both the physical and mental afflictions of the aging in order to ensure them as many healthy and happy years as possible.

Depression is a tremendous hindrance in the overall health of our nation's elderly population. Findings suggest that this high prevalence rate of depression in the elderly population is deeply concentrated in those who live in nursing homes or other long term care facilities. It is estimated that $25 \%$ of all nursing home residents experience clinical depression as opposed to $5 \%$ of those elderly seen in a primary care clinic and less than $3 \%$ of those who live in the community (NIH Consensus Statement, 1998). Because depression is often misdiagnosed or left untreated, this is considered to be a conservative estimate.

\section{Growth of At-Risk Population}

West Virginia has the highest median age of any U.S. state with the percentage of those over age 65 accounting for $15.1 \%$ of West Virginia's total population (West Virginia Profile of State Statistics, 1997). It is predicted that West Virginia will follow the national trend and experience a great increase in this number between the years 2010 and 2030 when the "Baby Boomer" generation reaches age 65. This dramatic increase in the number of elderly coupled with the number of chronic conditions that accompany old 
age could well result in an influx of the nursing home population. As a result, this will place even more of our state's elderly into a high-risk category for depression.

\section{$\underline{\text { West Virginia Nursing Homes }}$}

In West Virginia, the demand on the long term care system is high. The percentage of elderly who live alone is the second highest in the country. Those who currently live alone are most likely to end up in a nursing home (T. Dudley, personal communication, November, 1998). West Virginia is expanding nursing homes at an accelerated pace in order to meet the need of the already high elderly population. The state has been called "a good example of a state with a very high public demand that is attempting to meet that demand" (Administration on Aging, 1998).

Currently, West Virginia has 105 nursing home facilities throughout the state (T. Dudley, personal communication, November, 1998). These 105 nursing homes contain a total of 10,260 beds.

\section{Significance of the Proposed Work}

This epidemic of depression in the elderly, particularly those residing in nursing homes and the many complications associated with their treatment have not gone unnoticed by researchers. Researchers are trying to explain the origin of the statistical difference between the high prevalence of depression among facility residents versus those living in the community and seek an alternative solution. Fick (1993) addressed the issue by stating that, "Entering an institution can have a negative effect on a person's sense of well-being" (p. 529). This deterioration in physical health, mental health or both added to leaving one's home, personal belongings, family and pets has contributed to a 'patient's feeling disoriented, isolated, angry or depressed' (p. 529). This notion of a 
change in social environment is under increased scrutiny as an underlying contributor to depressed nursing home residents. According to Steuart (1993), the change the elderly experience in transitioning to a different role and social setting can affect family ties. The extent to which these family ties are maintained as before can vary widely for each individual. Many of these elderly are at a time in their lives in which they are least capable of comfortably adjusting to major social and identity changes, however, circumstances call for them to do so.

For those elderly who are living in nursing homes, this isolation and lack of social support from their networks is a concern. The findings from the Gospel Oak Project VI (Prince et al., 1997) addressed this issue. The Gospel Oak Project focused on a cross sectional relationship between depression and demographic variables, social support, and life events. A cross sectional survey interview was conducted with those who were 65 and older and lived in Gospel Oak, UK. The social support component of this study identified and measured six social support deficits including: living alone, seeing a relative less often than once a week, having no supportive neighbors, having one or less supportive friends, experiencing upset or bother in a relationship with a child, and experiencing dissatisfaction with support received from a friend.

The results of this study found strong evidence for a direct association between lack of social support and depression. Each social support deficit was moderately associated with depression. However, a positive correlation was noted in the number of social support deficits and depression suggesting a cumulative influence (Prince et al., 1997). 
These investigations suggest that direct interventions should look beyond treatment and prevention using pharmacotherapy and psychotherapy and look to the potential root of the problem-lack of social support. Although health promotion recommendations for the general pubic have been published during the last decade, health promotion for residents of long term care facilities has received less attention (Richardson, 1992). Supporting this notion, Burns (1993) found that treatment of mental illness among elderly nursing home residents has seldom been studied despite high rates of mental disorder in this population. This conjunction of a high prevalence rate of depression in nursing home residents and few health promotion activities, reinforces the idea that there is a great need for research in this area.

\section{$\underline{\text { Study Objectives }}$}

The proposed research is intended to reduce depressive symptoms in nursing home residents by using an intervention involving pet therapy to increase levels of social support and social interaction within the facility.

\section{$\underline{\text { Research Questions and Hypotheses }}$}

Research Question 1:

Will those residents who participate in an intervention using animal therapy have fewer depressive symptoms than those who do not participate?

\section{Hypothesis 1:}

Those residents participating in an intervention using animal therapy will experience fewer depressive symptoms than those who do not participate.

Research Question 2:

Will those residents who participate in an intervention using animal therapy seek 
social contact more often than before the intervention?

Hypothesis 2:

Those residents who participate in an intervention using animal therapy will seek more social contact than before the intervention. 


\section{Literature Review}

\section{Depression in the Elderly}

Depression is the most common emotional disorder in the elderly population and up to one-third of patients with medical disorders also suffer from depressive symptoms (Butler, 1995). Although these statistics may seem elevated, this may be a conservative estimate. "Psychiatric referral rates are low for American nursing home residents and are most often made for advice regarding behavioral disturbances rather than depression" (Ames, 1993, p. 387). Therefore, many residents are referred to their primary care physician in which case depression is often overlooked or misdiagnosed. "The elderly tend not to report depressive symptoms such as sadness or feelings of guilt because they may be embarrassed about their feelings or assume they are just a part of 'old age'. Instead, signs are manifested as physical complaints-sleep problems, anorexia or fatigue" (Butler, 1997, p. 7). Therefore, the underlying depression remains untreated.

Oftentimes for the elderly it is a medical or abnormal psychological activity that necessitates nursing home care. It is these very disorders that tend to, "overshadow the depressive component from the caregiver's perspective" (Abrams, 1992, p. 316). This combination along with the patient's report of chiefly somatic symptoms (that could be the result of a depressive episode) makes depression much more difficult to diagnose and therefore to treat.

Depression can not only affect the general mood and overall well being of the afflicted, it can be deadly if left untreated. The suicide rate for those ages 85 and over is the highest of any age group at a rate of 67.6 suicides per 100,000. This figure is five times the national rate for all ages of 12 per 100,000 (Butler, 1997). Although those ages 
85 and older account for about $12 \%$ of the population, they commit $25 \%$ of all reported suicides.

\section{Treatment of Depression}

For those elderly diagnosed with depression there are several treatments that are currently being utilized. The first of these, pharmacotherapy, is the most common treatment prescribed for depression in the elderly. Tricyclic antidepressants (TCAs) and selective serotonin reuptake inhibitors (SSRIs) are the two drug classes of choice in treating depression in older persons (Reynolds, 1994). TCAs and SSRIs are associated with a more tolerable side effect profile. However, pharmacotherapy with elderly patients presents several precautionary measures that must be taken. Long term treatment of late life depression requires a consideration of the risk to benefit ratio to the patient (Reynolds, 1994). For the elderly, the adverse effects of the TCAs may be exaggerated. Regarding the SSRIs, a very low starting dose and gradual increase is necessary. They, particularly the very old, frail or medically ill patient, may be less tolerant of long acting SSRIs and may experience several adverse side effects (apathy, anorexia, and inappropriate antidiuretic hormone secretion). Given that many elderly are on different kinds of medications for other medical problems, prescribing antidepressants can increase the potential risk for drug-drug interactions (Reynolds, 1994).

Maintenance therapy is essential to the success of drug therapies due to the increased risk of recurrence of depression in persons age 60 an older. Maintenance therapy begins after diagnosed remission and must continue (with the same dose as in treatment) for four to six months. For those who are experiencing negative side effects, the maintenance of the drug for an extended period of time can bring about much 
discomfort and may also lead to discontinuation of use. This discontinuation increases the risk of reoccurrence of depression bringing the patient back to a pretherapy state (Reynolds, 1994).

Other treatments used for depression in the elderly are psychotherapy and electroconvulsive shock therapy (ECT). Interpersonal psychotherapy and cognitive behavior therapy are particularly useful in depression associated with bereavement, role transitions, interpersonal conflicts, social isolation, and other changes that are particularly common in later life, and are best accompanied with pharmacotherapy (Reynolds, 1994).

ECT, although considered to be very controversial, can be a very effective treatment of depression in older people. However, it is usually reserved for specific situations such as: suicidal depression, tricyclic antidepressant-resistant depression, and medical contraindications to tricyclic medications or other antidepressants. A course of four to eight treatments can be effective. However, there is a risk of memory impairment after a course of ECT, especially among geriatric patients.

\section{CES-D Depression Scale}

The Center for Epidemiologic Studies Depression Scale, or CES-D, was designed to measure a person's current state and be responsive to changes over time. This scale was designed for research and is not intended to be used as a diagnostic tool for depression. Therefore, the CES-D cannot determine the levels of depression, but evaluates the symptoms of depression a subject may be experiencing (Radloff \& Teri, 1986).

The use of the CES-D has been studied on a wide range of ages from junior high students to those over the age of 80 . Utilization of the CES-D with the elderly population 
has shown to be quite accurate. The CES-D yields a prevalence pattern consistent to selflabeling of depressive mood and clinical diagnosis. No significant effect for age was obtained when the CES-D scores were compared to scores upon a clinical diagnosis. Studies have shown that the CES-D is a good, or perhaps better, predictor of depression for older adults as for younger adults (Radloff \& Teri, 1986).

\section{Theoretical Framework}

Social support theory is often understood in several components either individually or in combination. These components consist of the following: the number of people in a person's social circle (or the number of resources they can offer), the adequacy of one's relationship (or the availability of the resource they supply), the individual's perception of social support, or an observable behavior (Lanza \& Revenson, 1993).

These components of support in any combination can come from what is considered an informal network (usually consisting of friends and family) or a formal network (usually consisting of, in this case, doctors or other health care providers) (Lanza \& Revenson, 1993). Informal networks often give an individual emotional support providing them with feelings of love, trust and caring. Formal networks often provide instrumental and informational support giving services, suggestions, and information to assist an individual with a problem (Heaney \& Israel, 1997).

It is this combination of the social support components and the types of social networks that are invaluable to an elderly person making so many life changes. Because the social networks of the elderly are greatly affected due to isolation caused by illness, relocation, or death of family and loved ones, the creation of social ties can be critical to 
the amount of social support one may receive. It has been found that the greater number of social ties one has to draw upon, the lower is the risk of morbidity and morality and better one's mental health (Berhman, 1985; Kessler, 1985).

\section{Animal Therapy and Social Support}

A proposed intervention using animal therapy to facilitate social networking and social interaction in a nursing home setting will address this need and contribute to a much needed body of knowledge concerning the treatment and prevention of depressive symptoms in this at-risk population.

Several studies related to the effect of interactions between animals and the elderly have been carried out with positive outcomes. Even brief contact with a caring animal has been shown to cheer the depressed and motivate the apathetic (Puotinen, 1996) and has also been found to improve self-esteem and increase social interactions among staff and other residents (Winkler et al., 1989). In a study done by Fick (1993), there was a significant difference between the number of verbal interactions between individuals when a dog was present than when a dog was absent. It was concluded that the presence of the dog provided a comfortable environment that was conducive to facilitating social interaction within a group. Fick also states that, "for those who are not activity-oriented, the presentation of a dog at the beginning of a verbal interaction group might serve as a transition into an activity group" (p. 533). This transition could perhaps lead to more social networking and interaction with others.

Findings from existing literature suggest that the use of animals as a catalyst for social interaction and social networking will ultimately lead to increased social support among residents in a nursing home setting. The "visits" of animals on a regular basis 
affords the residents an opportunity to meet other residents, volunteers, and nursing home staff. If gives them the opportunity to reminisce and share with one another creating a bond and developing comradery that could prove to be supportive in some fashion in the future.

This intervention using animal therapy also overcomes limitations of other types of interventions. If follows the suggestions of Steuart (1993) who asserts that “interventions need not only to focus upon existing support systems, but also to facilitate the formation of new support systems, and, as far as possible, decrease the proportion of isolated elderly in the population" (p. 119). The use of this type of community intervention will take into account those residents who may be experiencing depressive symptoms but have not been diagnosed or perhaps have been misdiagnosed. This intervention may also serve as a preventative measure for those who are not yet experiencing depressive symptoms. 


\section{Research Methods}

$\underline{\text { Study Population }}$

The intervention population was drawn from a pool of certified nursing homes in Monongalia County, WV. These nursing homes were matched on characteristics such as: number of residents, average age, and number of existing social activities, including the current implementation of pet therapy. Information on these factors was gathered from existing data such as internet sources, government reports and also from employees who are familiar with such information.

The nursing homes in this pool were assigned a number and one was chosen using a table of random numbers. The nursing home chosen by this method was contacted by the researcher. The researcher explained to the nursing home administration that their facility was chosen at random for the opportunity to participate in an intervention involving pet therapy. A brief synopsis of the intervention was given at this time (See Appendix F). The administration was told that the intervention would take approximately six weeks and would include an interview with residents during the first week, visitation with pets once a week for four weeks, and an interview the week after the last visit. The researcher explained that in order to participate, the facility would be asked to provide a list of residents (capable of participating in an interview) to the researchers, provide an attendance roster of activities for a six weeks period, and open the facility (or certain areas) for visitation with the pets. The researcher also explained to the nursing home administration that they could expect the researcher and research assistants to approach the residents (from the list provided by the facility) about their participation, conduct all interviews, and act as a liaison between the pet therapy volunteers and the 
nursing home facility. The researcher offered all material (the questionnaire and informed consent form) for review with the agreement to make changes as the facility saw fit. The first facility chosen agreed to participate in the study.

Upon recruitment of an intervention facility, another facility in West Virginia was nonrandomly chosen for control measures in order to match characteristics of the intervention group. Recruitment of a control facility was taken outside of Monongalia county due to a county-wide implementation of pet therapy in those nursing homes. A pool of nursing homes based on similar characteristics to the intervention facility regarding number of residents, average age, and the number of existing social activities excluding the use of pet therapy was collected. From this pool, a list was made. The researcher contacted the first nursing home on the list and explained that they have been chosen as a control group for a study regarding pet therapy and its effects on depressive symptoms (See Appendix G). The researcher explained to the nursing home administration that participation would include an interview with several of their residents and another interview that would take place five weeks later. The researcher explained that in order to participate they would be asked to provide a list of residents capable of taking part in an interview. The researcher informed the administration that they would be provided with a copy of the questionnaire and consent form ahead of time for their review and changes could be made as they saw necessary. It was made known that research assistants would approach the residents (from the list provided by the facility) to participate and conduct all interviews. As an incentive to participate, the researcher offered to organize four visitations (once a week for four weeks) from local 
church members to lead gospel singing at the nursing home facility after the final interview was conducted. The first nursing home contacted agreed to participate.

\section{The Study Sample}

The study sample within these populations was chosen by recommendation of the activities director from each facility. A list of names was requested of residents physically and psychologically capable of answering questions in an interview format.

\section{$\underline{\text { Research Design }}$}

A quasi experimental two groups design was used to assess the effectiveness of the intervention. Two nursing homes were selected for study. An intervention facility was chosen at random and a comparable facility was nonrandomly selected as a control group.

\section{Description of the Intervention}

The current study was proposed as a three month study in which the residents would be visited three days per week by the therapy dogs and their owners. The study was modified in several ways before the actual intervention began.

The duration of the visits with the dogs was also altered. The therapy dog owners were volunteers who visited all nursing homes in the intervention county at least once a month. Due to an already demanding visitation schedule, they agreed to visit with the intervention residents for one month at one day per week. The total time for each weekly intervention period was one to one and a half -hours each week. During these visits, three to four volunteer owners, their dogs and researchers toured the facility taking the pets to each individual room. The volunteers asked the resident if they would like to visit with the dogs before entering their rooms. If the resident agreed, the dogs were brought 
in one at a time for the resident to visit with for a few minutes with the option of petting the dog. If the resident declined the visit or had a negative reaction when the dog was brought into the room, volunteers and dogs moved on to the next room. The pets were also taken to public areas of facility such as the lobby, cafeteria, and hallways to give those residents not in their rooms the opportunity to participate.

The control nursing home received a delayed intervention following posttest involving volunteers from a local church. These volunteers visited the control nursing home once a week for four weeks. These visits were marked on each resident's "social calendar" along with their regularly scheduled monthly activities. During these visits, the volunteers offered hymnals to residents who would like to participate in gospel singing. Those who wished not to sing were invited to come and listen.

\section{$\underline{\text { Data Collection Procedures }}$}

Data collection for the animal therapy intervention involved two techniques: a personal interview using a questionnaire format and natural observation.

\section{$\underline{\text { Personal Interview }}$}

Before pretest, researchers approached those residents (in both the intervention and control groups) recommended by the activities director and explained to them the nature of the study. These residents were offered the consent form (See Appendices D and E) and therefore the opportunity to participate.

During the pretest phase, trained interviewers conducted structured interviews with all nursing home residents in both the intervention and control samples who had given consent to participate. Researchers asked the residents questions from a questionnaire (See Appendix A) in an interview format and recorded their responses on 
the questionnaire form. The contents of the questionnaire included: demographics (such as age, marital status and state they are originally from), social support of family, social support of friends, social support of the nursing home environment, psychological measures regarding depression, and open ended questions about perceived quality of life in the nursing home. Questions regarding personal feelings about animals were also asked during this interview. The majority of the questions on the questionnaire were closed ended. However, several questions were left as open ended, therefore leaving the opportunity for the interviewee to express their feelings about an issue and offer suggestions.

During the posttest phase, an interview was conducted with both groups in the same format as used in pretest. The questions asked between groups in posttest (See Appendices B and C) were similar to those asked in pretest, with the exception of process measures to assess the effectiveness of the intervention.

\section{$\underline{\text { Natural Observation }}$}

During the pet therapy visits, the researcher and research assistants observed all interactions with the volunteers, their dogs, and the residents. During the visits to the resident's rooms and the public areas (hallways, cafeteria, and lobby), the research assistants kept a distance (approximately three feet) from the resident during their interaction with the pets and unobtrusively recorded certain aspects of their reactions. Interaction between the resident and research assistants did not occur until after the volunteer and dog left the room.

During these observations, researchers took note of the approximate number of residents participating each week, the number of areas (including resident's rooms) that 
were visited, the total number of negative reactions, and the total number and type of positive reactions (petting the dogs, speaking to the dogs or speaking to the owners). Resident's comments during the intervention were also recorded. These observations and comments were coded and examined for similarities and changes to supplement the qualitative findings of the interviews.

Another aspect of natural observation took place in the record keeping regarding the number of residents who have attended activities held by the facility. A record of attendance (of all members of the nursing home) to each activity was recorded one week prior to the intervention, during the intervention and for one week afterwards. These records were kept to assess increased interaction in other activities in the nursing home. This number was tallied at certain points in the intervention and used for additional data.

\section{Evaluation}

Main Study Variables: Operationalizations of the study variables are listed below.

1. Depressive Symptoms: These symptoms were measured according the score on the CES-D (Radloff, 1977). Responses to all questions are averaged to produce an index of depression scored 0 to 7 . The higher the score on the index, the more depressive symptoms are being exhibited.

A. CES-D short form measurement questions:

Respondents were asked, "how many days during the past week have you..." for each of the following questions. Responses include a scale of 0-7 for each question.

a. Felt you could not shake off the blues even with help from family or friends?

b. Had trouble keeping your mind on what you were doing?

c. Felt that everything you did was an effort?

d. Had sleep that was restless?

e. Felt lonely?

f. Felt sad?

g. Felt you just couldn't get going?

2. Social Interactions (Networks)-The following questions were used to assess how often a resident seeks social interactions within the nursing home setting. All responses were left open ended with the exception of $\mathrm{C}$ in which the subject answered yes or no. 
A. How many times a day do you talk with another resident?

B. How many times a day do you talk with a worker here at (name of facility) ?

C. Do you attend the activities they offer here at ?

D. How many different residents do you see or talk to each day $?$

3. Social Support-The following questions were used to assess the amount of social support a resident receives from family and friends outside of the nursing home facility. Response categories follow each question.

A. How often do you see, write or talk on the telephone with your relatives?

1. Nearly everyday

2. At least once a week

3. A few times a month

4. A few times a year

5. Hardly ever

B. How many relatives do you feel close to? (How many would you feel close enough to if you needed to talk about personal matters or needed help)? This question requires an open-ended response.

C. Are there any fellow residents that you feel especially close to (enjoy talking or spending time with)?

1. Yes 2. No

D. Are there any workers here at the nursing home that you feel especially close to (enjoy talking and spending time with)?

1. Yes 2. No

E. Are there any friends outside the nursing home that you feel especially close to? 1. Yes 2. No

F. How many times per week do you see, write or talk on the phone to friends outside the nursing home?

This question requires an open-ended response.

\section{Process Measures}

Process measures were conducted during the intervention to assess how the intervention was implemented and whether changes needed to be made. This was done by collecting observational data (resident comments) and comments from the facility staff. Process measures were also conducted at the conclusion of the intervention in the last interview. These questions were more qualitative in nature. They were included in the final interview to assess any immediate effects of the intervention, changing attitudes 
toward social interaction, and the type of effects the intervention had produced. Included in those questions were the following:

A. Have you participated in more activities than you used to? (before the intervention) 1. Yes 2. No

B. Would you like to see the animals:

1. More often

2. Less often

3. The same amount of time you already see them?

C. Do you feel like you got to know anyone who you did not know before?

1. Yes 2. No

D. What did you like most about the visits from the pets?

This question requires an open ended response.

E. What are some other things you may be interested in doing here at

This question requires an open ended response.

Interviewer remarks were also used as process measures to ensure the validity

of the pre and posttest measures. These remarks included the following questions:

1. Respondent's cooperation was: very good, good, fair or poor

2. Did the respondent misunderstand or have difficulty with any section of the questionnaire? Circle all that apply:

a. Social support (relatives)

b. $\quad$ Social support (friends)

c. Social support (nursing home)

d. Psychological measures (month)

e. Psychological measures (week)

f. Open-ended questions

3. Overall interview quality was:

\section{$\underline{\text { Data Analysis }}$}

Data from pretest, posttest, and all observational data was coded and entered into the SPSS statistical computer system. Descriptive statistics were conducted to present an overall picture of the social support characteristics and the prevalence of depressive symptoms for both the intervention and control groups. To analyze hypothesis one, the group mean CES-D score was calculated at both pretest and posttest for both groups. A paired samples t-test will was used to compare pretest and posttest means both between 
and within groups. To analyze hypothesis two, a one way ANOVA was calculated to examine a change in each communication variable across tests within the intervention group and also between the intervention and control groups. To supplement the data, qualitative data was analyzed for patterns based on frequencies. 


\section{Results}

\section{Observational Findings}

\section{Pet Therapy Visits}

During the pet therapy visits, an average of four volunteers and their dogs (one therapy dog per volunteer) visited each resident's room (with their permission) and also public areas of the facility such as the lobby, cafeteria and hallways giving those residents not in their rooms the opportunity to participate. The approximate time spent with each resident was two to three minutes. The approximate time visiting the whole facility was one to one and a half-hours each week, depending on the number of residents wanting to participate.

For the purposes of this study, all residents (both those in the sample and others who were not interviewed) in the intervention facility were offered the opportunity to visit with the pets and volunteers. Observational data was collected and examined involving all residents in the facility including those who were and were not considered part of the sample.

During the intervention, observational data for the intervention group was collected by research assistants while the visits took place. Researchers noted: the approximate number of residents participating, the number of rooms that were visited, the number of public areas that were visited, the number of negative reactions and the number and type of positive reactions exhibited. These findings were calculated for each visit.

The number of rooms visited indicates the rooms of those residents who agreed to let the dogs come into their rooms to visit. Those rooms that were not visited include: the rooms of those residents who were absent, sleeping, nonresponsive, or refused the visit. 
The number of negative reactions include those residents who verbally said they did not want to see the dogs, moved away from the animals, or acted distressed at the animal's presence.

The number of positive reactions include the subheadings in that category and also those residents who smiled, laughed, or showed other signs of happiness toward the animals during the visits.

\section{Table 1}

\begin{tabular}{ll}
\hline \multicolumn{1}{c}{ Visit One } \\
\hline Approximate number of residents visited & 50 \\
Number of public areas visited & 2 \\
Number of resident's rooms visited & 26 \\
Total negative reactions & $14 \%$ \\
Total positive reactions & $78 \%$ \\
$\quad$ Pet the dogs & $87 \%$ \\
$\quad \begin{array}{l}\text { Initiated conversation with } \\
\text { the pet owners }\end{array}$ & $28 \%$ \\
$\quad$ Spoke to the dog & \\
Related the therapy dog to an & $54 \%$ \\
old pet & $6 \%$ \\
\hline
\end{tabular}

During the first visit, approximately 50 residents were visited either in their rooms, the hallway or the cafeteria. The visits were met with an overall positive response of $78 \%$. Fourteen percent of the residents responded negatively, and the remaining $8 \%$ were nonresponsive. Most of the residents who responded positively pet the dogs (87\%), and over half (54\%) spoke to the dogs. Only $28 \%$ initiated a conversation with the pet owners during the visit. 


\section{Table 2}

\begin{tabular}{ll}
\hline \multicolumn{1}{c}{ Visit Two } \\
\hline Approximate number of residents visited & 55 \\
Number of resident's rooms visited & 29 \\
Number of public areas visited & 3 \\
Total negative reactions & $16 \%$ \\
Total positive reactions & $73 \%$ \\
Pet the dogs & $80 \%$ \\
Initiated conversation with the & $45 \%$ \\
pet owners & \\
Spoke to the dog & $55 \%$ \\
Related the therapy dog to an & $5 \%$ \\
old pet & \\
\hline
\end{tabular}

During the second visit, approximately 55 residents were visited either in their rooms, the facility lobby, hallway, or cafeteria. The visits were met with an overall positive response of $73 \%$. Sixteen percent of the residents responded negatively, and the remaining $11 \%$ were nonresponsive. Most of the residents who responded positively pet the dogs $(80 \%)$, and over half (55\%) spoke to the dogs. More residents initiated a conversation with the pet owners at visit two than in visit one $(45 \%)$.

\section{Table 3}

\begin{tabular}{ll}
\hline \multicolumn{1}{c}{ Visit Three } \\
\hline Approximate number of residents visited & 40 \\
Number of resident's rooms visited & 24 \\
Number of public areas visited & 1 \\
Total negative reactions & $8 \%$ \\
Total positive reactions & $83 \%$ \\
Pet the dogs & $94 \%$ \\
Initiated conversation with the & $70 \%$ \\
pet owners & \\
Spoke to the dog & $61 \%$ \\
Related the therapy dog to an & $15 \%$ \\
old pet & \\
\hline
\end{tabular}

During the third visit, approximately 40 residents were visited either in their rooms or in the hallway. The visits were met with an overall positive response of $83 \%$. Eight percent of the residents responded negatively, and the remaining eight percent were 
nonresponsive. Most of the residents who responded positively pet the dogs (94\%), and over half $(61 \%)$ spoke to the dogs. Seventy percent of the residents visited initiated a conversation with the pet owners during the visit.

\section{Table 4}

\begin{tabular}{ll}
\hline \multicolumn{1}{c}{ Visit Four } \\
\hline Approximate number of residents visited & 45 \\
Number of resident's rooms visited & 17 \\
Number of public areas visited & 2 \\
Total negative reactions & $4 \%$ \\
Total positive reactions & $87 \%$ \\
$\quad \begin{array}{l}\text { Pet the dogs } \\
\text { Initiated conversation with the }\end{array}$ & $100 \%$ \\
pet owners & $69 \%$ \\
Spoke to the dog & $49 \%$ \\
Related the therapy dog to an \\
old pet
\end{tabular}

During the fourth and final visit, approximately 45 residents were visited either in their rooms, the hallway or the cafeteria. The visits were met with an overall positive response of $87 \%$. Four percent of the residents responded negatively, and the remaining $9 \%$ were nonresponsive. All of the residents who responded positively pet the dogs (100\%), and almost half (49\%) spoke to the dogs. Sixty-nine percent initiated a conversation with the pet owners during the visit. 


\section{$\underline{\text { Record of Activities }}$}

\section{Resident Attendance to Weekly Facility Activities}

Table 5

\begin{tabular}{llll}
\hline & $\begin{array}{l}\text { Number Residents } \\
\text { Attending Activities Per } \\
\text { Week }\end{array}$ & $\begin{array}{l}\text { Percentage Change from } \\
\text { Previous Week }\end{array}$ & $\begin{array}{l}\text { Percent Change from } \\
\text { First Week }\end{array}$ \\
$\begin{array}{l}\text { Week 1 (before the } \\
\text { intervention) } \\
\text { Total number } \\
\text { Attending }\end{array}$ & 204 & & \\
$\begin{array}{l}\text { Week 2 } \\
\text { Total number } \\
\text { Attending }\end{array}$ & 212 & & \\
$\begin{array}{l}\text { Week 3 } \\
\text { Total number } \\
\text { Attending }\end{array}$ & 184 & $4 \%$ & $4 \%$ \\
$\begin{array}{l}\text { Week 4 } \\
\text { Total number } \\
\text { Attending }\end{array}$ & 196 & $-13 \%$ & $-10 \%$ \\
$\begin{array}{l}\text { Week 5* } \\
\text { Total number } \\
\text { Attending }\end{array}$ & 147 & $6 \%$ & $-4 \%$ \\
$\begin{array}{l}\text { Week 6* (after } \\
\text { intervention) } \\
\text { Total number } \\
\text { Attending }\end{array}$ & 137 & $-25 \%$ & $-28 \%$ \\
$*$ indicates missing data & & & \\
\hline
\end{tabular}

In order to determine if residents are seeking more social contact throughout the intervention period and afterward, the intervention facility activities staff was asked to keep an attendance roster for activities one week before the pet therapy intervention, through the intervention period, and for one week afterwards. These tallies were kept for all residents including those who were and were not part of the sample. The number of regular activities was consistent every week.

During the week before the intervention, the total attendance for all activities was 204. The second week, the week the intervention began, the actual number of attending residents increase 4\%. However, the remaining weeks (weeks three through six) declined in both the comparison categories of the previous week and the first week. The 
exception, however, was during week four in which the total number attending increased six percent. For this week, there was still a decrease in comparison to the first week's attendance (4\%).

\section{$\underline{\text { Analytical Findings }}$}

\section{$\underline{\text { Sample Characteristics }}$}

Both the intervention and control nursing homes care for primarily older individuals with chronic health problems. Many of the residents are confused and disoriented; some are considered to be very alert. Most are wheelchair bound and need assistance attending activities.

Due to the fact that few were considered (by the facility administration) to be both psychologically and physically capable of participating in an interview, many were unable to be evaluated. Fifteen subjects were recommended by the intervention facility. Of those fifteen subjects, one male and 10 females participated in both pretest and posttest. Two residents declined to participate at pretest, one subject was unable to be understood by the researcher, and the family of one resident refused to let the resident participate and filled out the questionnaire themselves. Table 6 shows the characteristics of the intervention sample. 


\section{Table 6}

\begin{tabular}{ll}
\hline Demographic & Percentage \\
& \\
\hline Sex & \\
Number of Males & 1 \\
Number of Females & 10 \\
Age & \\
$66-75$ & $9 \%$ \\
$76-85$ & $64 \%$ \\
$86-95$ & $27 \%$ \\
Marital Status & \\
Married & $9 \%$ \\
Divorced & $9 \%$ \\
Widowed & $82 \%$ \\
Home State & \\
West Virginia & $45 \%$ \\
Ohio & $9 \%$ \\
Pennsylvania & $18 \%$ \\
Maryland & $9 \%$ \\
Other & $9 \%$ \\
Average Stay & 2.4 Years \\
\hline
\end{tabular}

Fifteen subjects were also recommended by the nursing home administration of the control facility. Of those subjects, seven males and three females participated in both pretest and posttest. Two residents declined to participate at pretest, two residents were hospitalized at the time of pretest, and one subject was no longer at the facility at the time of posttest. Table 7 shows the characteristics of the control sample. 


\section{Table 7}

\begin{tabular}{ll}
\hline Demographic & Percentage \\
\hline Sex & \\
Number of Males & 7 \\
Number of Females & 3 \\
Age & \\
Under 55 & $9 \%$ \\
$56-65$ & $18 \%$ \\
$66-75$ & $18 \%$ \\
$76-85$ & $9 \%$ \\
$86-95$ & $36 \%$ \\
Marital Status & \\
Married & $18 \%$ \\
Divorced & $27 \%$ \\
Widowed & $45 \%$ \\
Never Married & $9 \%$ \\
Home State & \\
West Virginia & $73 \%$ \\
Ohio & $9 \%$ \\
Kentucky & $9 \%$ \\
Other & $9 \%$ \\
Average Stay & 2.8 Years \\
& \\
\hline
\end{tabular}

\section{$\underline{\text { Baseline CES-D Scores }}$}

To calculate the score on the abbreviated CES-D depression inventory, each sample resident was asked a series of seven questions (each considered to be a depressive symptom). Their responses to these questions consisted of how many days per week they were exhibiting each symptom. To calculate a mean depression rating, the number of days they were exhibiting each symptom was totaled and divided by the number of symptoms they were experiencing. This mean provided a range of 0 to 7 with the higher number indicating more depressive symptoms being exhibited.

At pretest, the mean intervention group CES-D score was $3.49(\mathrm{SD}=1.91)$ and the mean control group CES-D score was $2.25(\mathrm{SD}=2.22)$. 


\section{$\underline{\text { Communication Variables at Baseline }}$}

Four variables were examined to determine the amount of social support both the intervention and control groups were seeking at the time of pretest: how often the resident sees, writes or talks on the telephone with relatives ( $1=$ nearly everyday to $5=$ hardly ever); how often the resident sees, writes or talks on the telephone with friends outside the facility ( $1=$ nearly everyday to $5=$ hardly ever); how many times per day the resident sees or talks to other residents (exact number); and how many times per day the resident sees or talks to staff at the nursing home (exact number). To investigate each variable in which the subject would seek more social interaction, the response mean and standard deviation was calculated by variable for each group.

\section{Median Response for Each Communication Variable at Pretest}

\section{Table 8}

\begin{tabular}{|c|c|c|c|c|}
\hline & \multicolumn{2}{|c|}{ Intervention Pretest } & \multicolumn{2}{|c|}{ Control Pretest } \\
\hline Variable & Median & Number & Median & Number \\
\hline $\begin{array}{l}\text { Number of } \\
\text { times see, } \\
\text { talk, or write } \\
\text { to relatives }\end{array}$ & 2 & 11 & 3 & 10 \\
\hline $\begin{array}{l}\text { Number of } \\
\text { times see, } \\
\text { talk or write } \\
\text { to friends }\end{array}$ & 2 & 10 & 3 & 10 \\
\hline $\begin{array}{l}\text { Number of } \\
\text { times see or } \\
\text { talk to other } \\
\text { residents }\end{array}$ & 4 & 11 & 1 & 9 \\
\hline $\begin{array}{l}\text { Number of } \\
\text { times see or } \\
\text { talk to } \\
\text { nursing home } \\
\text { staff }\end{array}$ & 5 & 10 & 3 & 10 \\
\hline
\end{tabular}




\section{$\underline{\text { Intervention Communication }}$}

At pretest, most residents in the intervention facility reported seeing or talking on the phone with their relatives at least once a week; reported seeing or talking on the phone with friends at least once a week; reported seeing or talking to other residents approximately four times per day; and residents reporting feeling close to some staff members at the nursing home reported seeing or talking to them approximately three times per day.

\section{Control Communication}

At pretest, most control residents reported seeing or talking on the telephone to relatives few times a month; reported seeing or talking on the telephone to friends a few times per month; reported seeing or talking to other residents approximately once per day; and residents reporting feeling close to some staff members at the nursing home reported seeing or talking to them approximately five times per day.

\section{Differences Between Groups}

\section{$\underline{\text { Intervention and Control CES-D Differences }}$}

At pretest, the mean CES-D score for the intervention group $(\mathrm{M}=3.49, \mathrm{SD}=1.91)$ was higher than the mean CES-D score of the control group $(\mathrm{M}=2.25, \mathrm{SD}=2.22)$. Statistical analysis revealed a significant difference between the two group CES-D scores at pretest; $\mathrm{t}(20)=4.264, \mathrm{p}<.05$. Therefore, at pretest, the intervention group was experiencing more depressive symptoms (a mean difference of 1.25). 


\section{$\underline{\text { Intervention and Control Differences in Social Interaction }}$}

To assess the difference between groups in regards to how often they seek social interaction, a one way analysis of variance was computed for each variable regarding social interaction between the intervention and control groups.

\section{One Way Analysis of Variance Report at Pretest Between Groups for}

\section{Each Communication Variable}

Table 9

\begin{tabular}{llllll}
\hline Source & DF & SS & MS & F Value & Probability \\
\hline See, write or talk to relatives & 1 & 7.093 & 7.093 & 9.527 & .334 \\
See, write or talk to friends & 1 & 1.800 & 1.800 & 1.006 & .329 \\
See or talk to other residents & 1 & 7.152 & 7.152 & 1.698 & .209 \\
See or talk to staff members & 1 & 22.050 & 22.050 & 2.785 & .112 \\
\hline
\end{tabular}

The analysis of variance for the variable measuring how often a resident sees, writes or talks on the telephone to relatives between groups at pretest; $F(1,20)=9.527$, p>.05; how often a resident sees, writes, or talks on the telephone to friends between groups at pretest; $F(1,19)=1.006, \mathrm{p}>.05$; how often a resident sees or talks to other residents between groups at pretest; $\mathrm{F}(1,20)=1.698, \mathrm{p}>.05$; and how often a resident sees or talks to members of the nursing home staff between at pretest revealed no significant difference; $F(1,19)=2.785, \mathrm{p}>.05$.

\section{$\underline{\text { Main Findings }}$}

\section{Hypothesis One}

The first hypothesis stated that the intervention group would have a lower score at posttest on the CES-D abbreviated form (and therefore fewer depressive symptoms) than those who did not receive the intervention. To assess this, the score of each subject's CES-D responses was calculated. From those scores, a group mean was computed at 
both pretest and posttest for both groups and a paired samples t-test was used to further analyze the differences between the various tests.

\section{Mean CES-D Scores and T-Values Within Groups Across Tests}

\section{Table 10}

\begin{tabular}{llll}
\hline & Pretest & Posttest & T-Value \\
\hline $\begin{array}{l}\text { Intervention (M) } \\
\mathrm{N}=11\end{array}$ & 3.49 & 3.67 & $4.583^{*}$ \\
$\begin{array}{l}\text { Control (M) } \\
\mathrm{N}=11\end{array}$ & 2.25 & 1.44 & $-2.111^{*}$ \\
T-Value & $4.264^{*}$ & $4.264^{*}$ & \\
\hline
\end{tabular}

*Indicates a significance level of .05 .

The group mean CES-D score for the intervention group increased at posttest $(\mathrm{M}=3.67, \mathrm{SD}=2.22)$. Statistical analysis reveal a significant difference between the pretest and posttest scores; $\mathrm{t}(21)=4.583, \mathrm{p}<.05$. This increase in mean scores from pretest to posttest indicates a significant increase in mean depressive symptoms exhibited by the intervention residents.

The group mean CES-D score for the control group decreased at posttest $(\mathrm{M}=1.44, \mathrm{SD}=1.66)$. Statistical analysis reveal a significant difference between the pretest and posttest scores; $\mathrm{t}(20)=-2.111, \mathrm{p}<.05$. This decrease in mean scores from pretest to posttest indicates a significant decrease in the mean depressive symptoms exhibited by the control residents.

Statistical analysis also revealed a significant difference between the intervention group mean CES-D score and the control group mean CES-D score at posttest: $t$ $(21)=4.264, p<.05$. This difference in mean group scores indicates that the intervention group is exhibiting significantly more depressive symptoms than the control group at posttest. 


\section{Hypothesis Two}

The second hypothesis stated that those residents who received an intervention using pet therapy would be more likely to seek out social contact than those who did not receive the intervention. To investigate the extent to which this group sought social interaction at posttest (as compared to pretest) a one way analysis of variance was calculated across tests within the intervention group.

$\underline{\text { Intervention Group ANOVA Results }}$

\section{One Way Analysis of Variance Report Across Tests Within the Intervention Group for Each Communication Variable}

Table 11

\begin{tabular}{lccccc}
\hline Source & DF & SS & MS & F Value & Probability \\
\hline See, write or talk to relatives & 1 & .182 & .182 & .500 & .488 \\
See, write or talk to friends & 1 & .800 & .800 & .497 & .490 \\
See or talk to & 1 & .727 & .727 & .167 & .687 \\
Other residents & 1 & 6.656 & 6.656 & .410 & .530 \\
See or talk to & & & & & \\
Staff members & & & & & \\
& & & & & \\
\hline
\end{tabular}

The analysis of variance for the variable measuring how often a resident sees, writes, or talks on the telephone to relatives between pretest and posttest; $F(1,20)=.500$, p>.05; how often a resident sees, writes or talks on the telephone to friends between pretest and posttest; $F(1,19)=.497, \mathrm{p}>.05$; how often a resident sees or talks to other residents between pretest and posttest; $\mathrm{F}(1,20)=.167, \mathrm{p}>.05$; and how often a resident sees or talks to members of the nursing home staff between pretest and posttest revealed no significant difference; $\mathrm{F}(1,20)=.410, \mathrm{p}>.05$.

\section{Group Comparison ANOVA}

To assess group differences regarding the amount of social interactions residents were seeking at posttest, a one way analysis of variance posttest group comparison was 
calculated.

\section{One Way Analysis of Variance Report Between Groups at Posttest for Each Communication Variable}

Table 12

\begin{tabular}{llllll}
\hline Source & DF & SS & MS & F Value & Probability \\
\hline See, write or talk to relatives & 1 & 5.725 & 5.725 & 7.144 & $.015^{*}$ \\
See, write or talk to friends & 1 & 1.250 & 1.250 & .824 & .376 \\
See or talk to other residents & 1 & 1.456 & 1.456 & .488 & .511 \\
See or talk to staff members & 1 & 5.528 & 5.528 & .309 & .585 \\
& & & & & \\
\hline
\end{tabular}

*Indicates a significance level of .05 .

The analysis of variance for the variable measuring how often a resident sees, writes, or talks on the telephone to relatives between groups at posttest revealed a significant difference; $F(1,20)=7.144, \mathrm{p}<.05$. Therefore, the control group was communicating with their relatives significantly more at posttest than the intervention group. How often a resident sees, writes, or talks on the telephone to friends between groups at posttest; $\mathrm{F}(1,19)=.824, \mathrm{p}>.05$; how often a resident sees or talks to other residents between groups at posttest; $\mathrm{F}(1,20)=.488, \mathrm{p}>.05$; and how often a resident sees or talks to members of the nursing home staff between groups at posttest revealed no significant difference; $F(1,20)=.309, \mathrm{p}>.05$. 


\section{$\underline{\text { Study Limitations }}$}

\section{Discussion}

The intervention nursing home had previously been receiving pet therapy visits one day per month (lasting approximately one hour each visit). As such it might be difficult to discern differences in outcomes due to the intervention. However, the goal of this intervention was to increase the intensity of this already existing therapy in an attempt to facilitate social support and decrease the incidence of depressive symptoms in the nursing home residents. A one day per month intervention would be unlikely to change the outcomes measured in this study.

\section{$\underline{\text { Summary of Major Findings }}$}

\section{Hypothesis One}

The first hypothesis states that those residents participating in an intervention using animal therapy have fewer depressive symptoms than those who do not participate.

Findings showed a significant increase in CES-D scores in the intervention group from pretest to posttest indicating a slight increase in depressive symptoms. In the control group, CES-D scores at posttest indicated a decrease in depressive symptoms from pretest. These findings are in the opposite direction hypothesized.

One explanation for these results may lie in the difference in between-group mean CES-D scores at pretest. At pretest, the control group demonstrated a significantly lower mean CES-D score than the intervention group. Due to the increase in the intervention group's posttest t-score and a decreased group mean CES-D (from an already lower pretest score), the mean group difference between groups at posttest was high. This difference in the initial group mean CES-D scores is critical in subsequent group 
comparisons (involving mean CES-D comparisons with other variables) calculated in the study results.

The use of the CES-D itself may be a source of explanation for fewer depressive symptoms in the control group as opposed to the intervention group at both pretest and posttest. Gender differences in rates of depressive symptomology were found to be significant across the age span of 18 to 97 year old respondents (in previous studies). Women reported higher CES-D scores (Radloff \& Teri, 1986). The differences in demographics between the two groups in regards to the intervention (one male and 10 females) and the control group ( 7 males and 3 females) correlates with this finding. The intervention group was predominately female and showed significantly more depressive symptoms at both pretest and posttest than the predominately male control group.

Consideration should also be taken that those who are experiencing many depressive symptoms or who have been diagnosed as depressed are not likely to be willing to participate in the visitations with the pets. Therefore this intervention would not be reaching these individuals and the number of depressive symptoms is unlikely to be changed through the use of pet therapy.

It is very likely that the current intervention (or certain characteristics thereof) were not strong enough to bring the intervention group CES-D levels to that of the control group.

According to Puotinen (1996), even brief contact with a caring animal has been shown to cheer the depressed. Visitations with the pets during this study were considered to be brief to moderate (an average of 3 minutes with each resident) in duration. However, findings of this study were contradictory of those of Puotinen. After a four 
week intervention, depressive symptoms in the intervention group sample increased from pretest to posttest.

\section{Hypothesis Two}

The second hypothesis states that those residents participating in an intervention using animal therapy will be more likely to seek out social contact than before the intervention.

Findings showed slight increases in two components measuring the efforts of the intervention residents to seek out social contact. These residents were communicating with their relatives more often and seeing or talking to staff members at the nursing home more often in posttest than in pretest. However, there was a decrease in the other two components measuring efforts to seek social support. Intervention residents reported seeing or talking to friends and other nursing home residents less often at posttest than at pretest.

Findings in the control group showed a slight increase in the number of times those residents reported seeing or talking on the telephone to relatives and in the number of times per day they saw or talked to other residents. However, residents reported seeing or talking to friends and nursing home staff less during this period.

When these results were examined further using an ANOVA, there were no significant differences between groups at pretest nor was there any significant differences in the intervention group between pretest and posttest. Although there were slight mean comparison differences, they were not significant enough to identify a relationship. This lack of significant change could be partially attributed to two known factors: the short 
amount of time between pretest and posttest and also a case of the flu that had spread through the control nursing home the week before posttest.

Due to the fact that many of the respondents in both groups have resided in these homes a mean of 2.6 years, it is possible that their daily routines such as visiting with friends, family and other nursing home residents and staff are already established. Because the intervention time lasted only four weeks, this time may not have been sufficient enough to alter established routines.

Over half of the control residents interviewed at posttest reported having flu like symptoms the previous week. This illness could potentially affect the responses to questions about visiting with family, friends, etc... The control group reported an increase in communication with relatives (shown to be significant between pretest and posttest). This possibly indicates that the resident was talking to or seeing relatives for additional help (or being contacted due to concern on the part of the relative) during the illness. There was also an increase in the number of times a resident saw or talked to a fellow resident during this period. This could be attributed to concern on the part of a friend within the facility.

Because study results produced mixed results in the areas in which residents were seeking more social contact, this study relates only partially to what has been found in previous studies. According to results found by Fick (1993), a dog provided a comfortable environment conducive to facilitating social interaction within a group. It is proposed that this interaction could perhaps lead to more social networking and interaction with others. Findings in the intervention group support this notion to an extent. There was an increase in the amount of social contact with nursing home staff 
(occasionally present during the visits) and also with relatives (who were not present during visits). However, a decrease in social interaction between pretest and posttest occurred with other nursing home residents (present during the visits) and friends (who were not present during the visits). Therefore, the results of this study appear to be divided in terms of agreement with the literature.

\section{Observational Findings}

\section{Pet Therapy Visits}

During the pet therapy visits, researchers watched and recorded the residents and their interactions with the dogs, owners, and on occasion with other researchers. Notes were made as to the type of reaction they had to the animals (positive or negative) and also their actions during the visits. Data was recorded from observations of all residents in the intervention nursing home including those who were and were not considered to be part of the sample.

Visit one was a regularly scheduled monthly visit from the pet owners. There were a relatively high number of positive reactions. The majority of the residents petted and spoke to the dogs. However, very few talked to the owners or related the dog to an animal from their past.

During visit two these numbers lowered overall. The number of positive reactions was still high. However, it was down from the previous visit as was the number of residents who pet the dogs. The number of residents who spoke to the dog and related the visit to an old pet remained almost the same. This could be attributed to an "irregular visit" from the once a month scheduled visit they are accustomed to. In fact, it was noted by one resident who said, "I didn't know they were coming today". Many aspects of 
living in the nursing home are very routine (such as the activities, meals, medication times, and on occasion visits from family members and friends). This break in routine could cause anxiety for some.

At the third week visit, noticeable changes were made during observations. The overall number of positive reactions increased. The number of residents who pet the dogs increased substantially, but perhaps the most dramatic increase was in the number of residents who talked to the owners of the dogs. The number of residents who spoke to the dogs and related the dog to an old pet increased as well.

The fourth week visit continued this upward trend in reactions to the pet visitations. The number of positive reactions continued to increase regarding those residents who pet the dogs and those who related the dog to a pet. The number of residents who spoke to the owners stayed almost the same. However, one decrease was noted in the amount of times residents spoke to the dog. This decrease could be attributed to more conversation being directed to the people instead of the animals.

The dramatic increase in interaction with the dogs and the owners during the third visit and afterwards indicates a feeling of comfort and familiarity with the visits. The residents were more involved in the intervention and their communication with others increased during these periods. Although this group had been previously visited on a regular basis, it seems as though the frequency of the intervention visits helped them to better remember the volunteers and their pets from week to week. The residents were initiating conversations with the pet owners and researchers much more often and reminiscing of pets they had when they lived "at home". Residents shared stories of past pets and even shared pictures of those pets with the visitors. One lady said she is going 
to get another dog, "when she goes home". Others talked about how much they miss having a pet around. One gentleman even went so far as to say that he likes dogs very much because, "sometimes they just make more sense than people do".

Although results from the interview indicated that the sample is not making a significant effort to increase their social interaction, it must be kept in mind that these numbers were largely in regards to friends and family. The questionnaire did not account for interaction with animal owners at pretest.

The sample size in relation to the population size should also be noted as an affecting factor. Other residents, those who were unable to participate in an interview, might be feeling largely positive effects from the intervention. However, these effects cannot be accurately measured due to difficulty in communication.

In regards to the intervention, sample subjects did show approval of the visits. Over half of the respondents said they would like to see the pets more often. When asked about what they liked best about the visits, many said they liked everything (seeing the animals, petting them and talking to the visitors) and one quarter responded that they liked petting the animals the best. A substantial number of subjects reported that they felt like they got to know someone new during the intervention period.

Although the findings of the questionnaire revealed an inconsistency with findings from the literature, the observational results appear to be in agreement in regards to group verbal interaction. Observations reveal that the residents did, in fact, interact more with those volunteers who visited along with their pets, especially during the last two visits. 


\section{$\underline{\text { Record of Activities }}$}

The activities director of the intervention home and her staff agreed previous to the intervention to record the attendance of residents at each activity. This recording took place every day for one week before the intervention, through the intervention period, and for one week afterwards. Upon examination of these records and percentages that were calculated comparing attendance to weekly activities, a steady drop was found in attendance every week (with the exception of week two). However, these results should be reviewed with caution. At the beginning of week three, several events were canceled due to groups (volunteer community groups) neglecting to show for an activity they were scheduled to oversee. This could have caused frustration with those residents looking forward to these events causing a decline in others throughout the week. Inconsistency in record keeping is also a factor in the declining percentages. In both weeks five and six, attendance for two or more days (each week) was not recorded. For purposes of the study, percentages were calculated regardless of the missing data.

Participation was also not recorded for those activities that did not take place in a central location (such as the pet therapy visits and certain craft activities in which the material was delivered to individual rooms). Therefore, numbers measuring the resident's increased attendance to facility activities should be read with caution. Implications of the Findings

The findings, both quantitative and qualitative, of the current study certainly warrant future investigations into the effectiveness of pet therapy in the reduction and prevention of depressive symptoms in nursing home residents. This type of intervention was enthusiastically welcomed by the intervention nursing home staff and also those 
volunteers approached to participate in the study. These positive reactions indicate that future, more in-depth, studies would also be welcomed by this population and therefore must be taken advantage of.

\section{$\underline{\text { Recommended Changes }}$}

The process of implementing the current study and analyzing the results revealed changes that would potentially benefit additional pet therapy studies. Perhaps the most important factor affecting a study of this type is the size of the sample. The current study examined one nursing home for intervention and one nursing home for control. Due to the nature of the population, the number of those who are capable (physically and psychologically) of answering questions in order to provide quantitative data are very limited. This obstacle could be overcome in two ways. A more detailed qualitative analysis involving all members of the population could reveal many aspects of emotion and interaction resulting form the intervention. This would allow researchers to obtain data from both those residents who communicate well and it would allow researchers to reach those who are unable to communicate effectively.

Another way to overcome this bias is to increase the size of the intervention sample by conducting the study in more nursing homes. By increasing the size of the sample population, a researcher is provided with more data upon which to base conclusions and make comparisons. It must be noted that perhaps another means of recruiting participants within the nursing home (aside from suggestions of the facility administration) should be employed to further eliminate bias and perhaps increase the sample size within these populations. 
Increasing the size of the study brings with it other implications as well. A pet therapy study depends greatly on the cooperation of volunteers and their pets. This commitment is often demanding on their time, and therefore many pet owners may be reluctant to increase the number of nursing homes visited or the length of the visits. Because of these demands, a financial incentive may be imperative for additional cooperation therefore requiring funding for future research.

Considerations also must be made that animals may not be the only venue to decrease the depressive symptoms in nursing home residents. Perhaps it is the combination of the animals and other people that provide the most effective means of reduction. Further investigations should not concentrate solely on one on one pet and resident visitation, but use the opportunity of the visits to gather several residents and volunteers in a group interaction situation. Another way to approach this issue would be to introduce a third group into the study (using an intervention). This third group would consist of a group interaction intervention (during the period between pretest and posttest) in order to better determine the effects of the person to person interaction on depressive symptoms and social interaction. 


\section{Pretest Questionnaire (Intervention and Control Group) Appendix A}

\section{$\underline{\text { Demographics }}$}

1. How long have you lived at ? (Enter institution name here)

2. What city are you from originally?

3. How old are you?

a. under 55

b. $56-65$

c. $\quad 66-75$

d. $\quad 76-85$

e. $86-95$

f. over 95

\section{$\underline{\text { Social Support }}$}

1. Are you currently:

Married

Divorced

Separated

Widowed

Never Married

\section{Social Support (Relatives)}

2. About how many of your close friends and relatives live in this area?

3. How are those people related to you?

a. Husband or Wife *Ask only if applicable

b. Children

c. Grandchildren

d. Brothers

e. Sisters

f. Other relatives

g. Non-relatives

4. How often do you see, write or talk on the telephone with your relatives?

a. Nearly everyday

b. At least once a week

c. A few times a month

d. A few times a year

e. Hardly ever

5. How many relatives do you see or hear from at least once a week?

6. How many relatives do you feel close to? (How many would you feel close enough to if you needed to talk about personal matters or needed help)?

7. How often do you get any kind of help from your family?

a. Very often 

b. Fairly often
c. Not often
d. Never

\section{Social Support (Friends)}

8. How often do you see, write or talk on the telephone with friends who do not live with you?
a. Nearly everyday
b. At least once a week
c. A few times a month
d. A few times a year
e. Hardly ever
9. How many friends do you see or hear from at least once a week?

10. How many friends do you feel close to? (enjoy talking to, spending time with?

11. How often do your friends give you any kind of help?
a. Very often
b. Fairly often
c. Not too often
d. Never

\section{$\underline{\text { Social Support (Nursing Home) }}$}

12. Are there any fellow residents that you feel especially close to (enjoy talking or spending time with)?

13. If so, how many times a day do you see/talk to them?

14. Are there any workers here at the nursing home that you feel especially close to (enjoy talking and spending time with)?

15. If so, how many do you see/talk to?

\section{Psychological Measures}

17. How many days during the past week have you:

a. Felt you could not shake off the blues even with help from family or friends?

b. Had trouble keeping your mind on what you were doing?

c. Felt that everything you did was an effort?

d. Had sleep that was restless?

e. Felt lonely?

f. Felt sad? 
g. Felt like you just couldn't get going?

\section{Open-ended Questions}

1. How do you feel about living at $?$

2. Do you attend the activities? If so, which ones do you like the best and why? If not, why not?

3. What would make living here better for you?

4. What do you dislike the most about living here?

5. Did you have pets while you were growing up? If so, what kind?

6. Did you continue to have pets through adulthood also? If so, what kind?

\section{Interviewer Remarks}

1. Respondent's cooperation was: very good, good, fair, poor

2. Did the respondent misunderstand or have difficulty with any section of the questionnaire? Circle all that apply:

a. $\quad$ Social support (relatives)
b. $\quad$ Social support (friends)
c. Social support (nursing home)
d. Psychological measures (month)
e. Psychological measures (week)
f. Open-ended questions

3. Overall interview quality was:
a. high
b. reliable 
c. questionable

d. unsatisfactory

4. The main reason for unsatisfactory or questionable quality of information was because respondent :
a. was disturbed by interruptions
b. was upset or withdrawn
c. was bored or uninterested
d. did not want to be more specific
e. was having trouble concentrating
f. was having trouble with hearing and/or speech
g. Was of questionable cognition
h. was unable to understand the questions
i. other 


\section{Posttest Questionnaire (Intervention Group) Appendix B}

Demographics

$\underline{\text { Social Support (Relatives) }}$

1. How often do you see, write or talk on the telephone with your relatives?

a. Nearly everyday

b. At least once a week

c. A few times a month

d. A few times a year

e. Hardly ever

2. How many relatives do you see or hear from at least once a week?

3. How many relatives do you feel close to? (How many would you feel close enough to if you needed to talk about personal matters or needed help)?

4. How often do you get any kind of help from your family?

e. Very often

f. Fairly often

g. Not often

h. Never

\section{Social Support (Friends)}

5. How often do you see, write or talk on the telephone with friends who do not live

with you?

f. Nearly everyday

g. At least once a week

h. A few times a month

i. A few times a year

j. Hardly ever

6. How many friends do you see or hear from at least once a week?

7. How many friends do you feel close to? (enjoy talking to, spending time with?)

8. How often do your friends give you any kind of help?

e. Very often

f. Fairly often

g. Not too often

h. Never

\section{Social Support (Nursing Home)}

9. Are there any fellow residents that you feel especially close to (enjoy talking or spending time with)?

10. If so, how many times a day do you see/talk to them?

11. Are there any workers here at the nursing home that you feel especially close to (enjoy talking and spending time with)?

12. If so, how many do you see/talk to? 


\section{$\underline{\text { Psychological Measures }}$}

13. How many days during the past week have you:

h. Felt you could not shake off the blues even with help from family or friends?

i. Had trouble keeping your mind on what you were doing?

j. Felt that everything you did was an effort?

k. Had sleep that was restless?

1. Felt lonely?

m. Felt sad?

n. Felt like you just couldn't get going?

\section{Open-ended Questions}

2. How do you feel about living at ?

3. What would make living here better for you?

4. What do you dislike the most about living here?

5. What did you like best about the visits with the pets?

7. What did you like least about the visits with the pets?

8. Would you like to continue seeing the pets more often like you have in the past month, less often, or once a month as before?

9. Have you participated in more activities than usual lately (since the pets have started visiting more or in the past month?)

10. Do you feel like you got to know anyone new during the visits with the pets (or in the last month)?

\section{Interviewer Remarks}


3. Respondent's cooperation was: very good, good, fair, poor

4. Did the respondent misunderstand or have difficulty with any section of the questionnaire? Circle all that apply:

g. Social support (relatives)

h. Social support (friends)

i. $\quad$ Social support (nursing home)

j. $\quad$ Psychological measures (month)

k. Psychological measures (week)

1. Open-ended questions

4. Overall interview quality was:

e. high

f. reliable

g. questionable

h. unsatisfactory

5. The main reason for unsatisfactory or questionable quality of information was because respondent :

j. $\quad$ was disturbed by interruptions

k. $\quad$ was upset or withdrawn

1. was bored or uninterested

m. did not want to be more specific

n. was having trouble concentrating

o. was having trouble with hearing and/or speech

p. Was of questionable cognition 
q. was unable to understand the questions

r. other 


\title{
Posttest Questionnaire (Control Group) Appendix C
}

\author{
Social Support (Relatives)
}

1. How often do you see, write or talk on the telephone with your relatives?
a. Nearly everyday
b. At least once a week
c. A few times a month
d. A few times a year
e. Hardly ever

2. How many relatives do you see or hear from at least once a week?

3. How many relatives do you feel close to? (How many would you feel close enough to if you needed to talk about personal matters or needed help)?

4. How often do you get any kind of help from your family?

i. Very often

j. $\quad$ Fairly often

k. Not often

1. Never

\section{Social Support (Friends)}

5. How often do you see, write or talk on the telephone with friends who do not live with you?

k. Nearly everyday

1. At least once a week

m. A few times a month

n. A few times a year

o. Hardly ever

6. How many friends do you see or hear from at least once a week?

7. How many friends do you feel close to? (enjoy talking to, spending time with)?

8. How often do your friends give you any kind of help?

i. Very often

j. Fairly often

k. Not too often

1. Never

\section{Social Support (Nursing Home)}

9. Are there any fellow residents that you feel especially close to (enjoy talking or spending time with)?

10. If so, how many times a day do you see/talk to them?

11. Are there any workers here at the nursing home that you feel especially close to (enjoy talking and spending time with)?

12. If so, how many do you see/talk to? 


\section{Psychological Measures}

13. How many days during the past week have you:

o. Felt you could not shake off the blues even with help from family or friends?

p. Had trouble keeping your mind on what you were doing?

q. Felt that everything you did was an effort?

r. Had sleep that was restless?

s. Felt lonely?

t. Felt sad?

u. Felt like you just couldn't get going?

\section{Open-ended Questions}

6. How do you feel about living at $?$

7. What do you dislike about living here?

8. Have you attended more activities in the past month than usual?

\section{Interviewer Remarks}

5. Respondent's cooperation was: very good, good, fair, poor

6. Did the respondent misunderstand or have difficulty with any section of the questionnaire? Circle all that apply:

m. Social support (relatives)
n. Social support (friends)
o. Social support (nursing home)
p. Psychological measures (month)
q. $\quad$ Psychological measures (week) 


\section{r. Open-ended questions}

5. Overall interview quality was:

i. high

j. reliable

k. questionable

1. unsatisfactory

6. The main reason for unsatisfactory or questionable quality of information was because respondent :

$\begin{array}{ll}\text { s. } & \text { was disturbed by interruptions } \\ \text { t. } & \text { was upset or withdrawn } \\ \text { u. } & \text { was bored or uninterested } \\ \text { v. } & \text { was having trouble concentrating } \\ \text { w. } & \text { was of questionable cognition } \\ \text { x. } & \text { was unable to understand the questions } \\ \text { y. } & \text { other }\end{array}$


Appendix D

\begin{abstract}
West Virginia University
Department of Community Medicine

Community Health Promotion

Consent and Information Form (Intervention Group)

Back to Nature to Beat the Blues
\end{abstract}

\title{
Introduction
}

I, have been invited to participate in this research study which has been explained to me by - This study is being conducted by Shannon Lawson from the Community Health Promotions Department at West Virginia University in order to complete the requirements for a master's degree.

\section{$\underline{\text { Purpose }}$}

It has been explained to me that the researchers are studying issues of health and aging in nursing home residents.

\section{Procedures}

I understand that I will be interviewed now and I will be interviewed again in approximately one month. I understand that the interview will take approximately 45 minutes to complete. I understand that I may look at the questions I will be asked prior to signing this consent form. I also understand that I do not have to answer all the questions asked. Everyone in this nursing home who is interviewed will be asked the same questions as I have been.

Initials Date Page 1 of 3 
Back to Nature to Beat the Blues (intervention group) Page 2 of 3

Procedures Cont.

Until I am interviewed for a second time, I will be visited on a regular basis by volunteers and their pets. I understand that I may be observed during these visits. I understand that my participation in the entire project will last approximately six weeks. Approximately 60 subjects will be involved in this study.

\section{Benefits}

By participating in the study, I am helping add to the body of knowledge that may improve the health of elderly persons. I will receive the benefits of visiting with volunteers and their pets who will come to the home.

\section{Risks and Discomforts}

I understand that I will be in the presence of animals at various times throughout the month. I also understand there may be an element of discomfort with answering questions that may seem personal.

\section{Alternatives}

I may choose not to participate in this research study.

\section{Contact Persons}

For more information about this research, I can contact Shannon Lawson at (304) 598-2957 or her advisor Dr. Irene Tessaro at (304) 2937510 ext. 0211. I also may contact the Executive Secretary of the Institutional Review Board at (304) 293-7073 for questions concerning my rights as a research subject.

Initials

Date 
Back to Nature to Beat the Blues (intervention group) Page 3 of 3

\section{Confidentiality}

I understand that any information about me obtained as a result of my participation in this research will be kept as confidential as legally possible.

Identification numbers on questionnaires are for keeping track of the questionnaires as they are returned and the information is recorded. Data will be seen by the research team only and will not be disclosed to others. Any publications using research findings from this study will not include my name or any other information from which I could be identified.

\section{Voluntary Participation}

I understand that participation in this study is voluntary. I understand that I am free to withdraw at any time. I have been given the opportunity to ask questions about the study and I have received answers concerning those areas I did not understand.

I voluntarily agree to participate in this research. Upon signing this form, I will receive a copy.

\begin{tabular}{llcr}
\hline Signature of Participant/Respondent & Date & & Time \\
\cline { 1 - 2 } & & Date & Time \\
\hline Signature of Interviewer & $\bar{n}$ & \\
\hline Signature of Witness (in the case the participant is unable to sign)
\end{tabular}


Appendix E

West Virginia University

Department of Community Medicine

Community Health Promotion

Consent and Information Form (Control Group)

Back to Nature to Beat the Blues

\section{Introduction}

I, have been invited to participate in this research

study which has been explained to me by - This study is being conducted by Shannon Lawson from the Community Health Promotions Department at West Virginia University in order to complete the requirements for a master's degree.

\section{$\underline{\text { Purpose }}$}

It has been explained to me that the researchers are studying issues of health and aging in nursing home residents.

\section{Procedures}

I understand that I will be interviewed now and I will be interviewed again in approximately one month. I understand that the interview will take approximately 25 minutes to complete. I understand that I may look at the questions I will be asked prior to signing this consent form. I also understand that I do not have to answer all of the questions asked. Everyone in this nursing home who has been interviewed will be asked the same questions as I have been.

Initials

Date

Page 1 of 3 
Back to Nature to Beat the Blues (control group) Page 2 of 3

\section{Procedures Cont.}

I understand that after I have been interviewed for the second time I will be asked to participate in entertainment activities such as crafts and singing provided by the researchers once a week for a period of one month. I understand that my total involvement in the study is approximately six weeks. Approximately 60 subjects will be involved in this study.

\section{Benefits}

By participating in the study, I am helping add to the body of knowledge that may improve the health of elderly persons. I will receive the benefits of visiting with volunteers who will come to the home.

\section{$\underline{\text { Risks and Discomforts }}$}

I understand there may be an element of discomfort with answering questions that appear to be personal.

\section{$\underline{\text { Alternatives }}$}

I may choose not to participate in this research study.

\section{Contact Persons}

For more information about this research, I can contact Shannon Lawson at (304) 598-2957 or her advisor Dr. Irene Tessaro at (304) 2937510 ext. 0211. I also may contact the Executive Secretary of the Institutional Review Board at (304) 293-7073 for questions concerning my rights as a research subject.

Initials

Date 
Back to Nature to Beat the Blues (control group) Page 3 of 3

\section{Confidentiality}

I understand that any information about me obtained as a result of my participation in this research will be kept as confidential as legally possible.

Identification numbers on questionnaires are for keeping track of the questionnaires as they are returned and the information is recorded. Data will be seen by the research team only and will not be disclosed to others. Any publications using research findings from this study will not include my name or any other information from which I could be identified.

\section{Voluntary Participation}

I understand that participation in this study is voluntary. I understand that I am free to withdraw at any time. I have been given the opportunity to ask questions about the study and I have received answers concerning those areas I did not understand.

I voluntarily agree to participate in this research. Upon signing this form, I will receive a copy.

\begin{tabular}{|c|c|c|}
\hline$\overline{\text { Signature of Participant/Respondent }}$ & Date & Time \\
\hline Signature of Interviewer & Date & Time \\
\hline
\end{tabular}

$\overline{\text { Signature of Witness (in the case the participant is unable to sign) }}$ 


\section{Intervention Group Proposal \\ Appendix F}

Project:

1. The focus of the project is on depression in the elderly, particularly those elderly living in a nursing home facility.

2. I am looking at types of intervention aside from drug therapy and psychotherapy to reduce symptoms of depression.

3. MonPointe has been chosen at random among all nursing home facilities in Monongalia County, WV for the chance to participate in the study. The facility will have the option to accept or decline to allow the study in their facility.

\section{What the Project Will Include:}

1. Two interviews will be done by Shannon Lawson and two other CHPR graduate students with a sample of residents in the facility. These interviews will be in a questionnaire format.

2. The time between the first and second interview will be approximately four weeks. The content of the second interview will be the same as the first with the exception of a few questions.

3. Intervention: The actual intervention will take place for four weeks between interviews. This will involve volunteer certified therapy animals, their owners, myself and two other graduate students visiting the residents. The number and length of the visits will be according to that which the facility feels appropriate.

\section{*All information collected during interviews will be kept confidential as noted in the consent form.}

\section{$\underline{\text { Responsibilities of the Researcher }}$}

1. The researcher will conduct all interviews with the residents.

2. The researcher will coordinate all volunteers and visits with the residents.

3. The researcher will provide the staff, residents, and their families (who are interested) with a copy of the findings after the study is complete and data has been analyzed. 
What is Asked of the Facility

1. Assist the interviewers in identifying those residents who are able (physically and mentally) to be interviewed.

2. The use of the facility for "visits" with pets.

3. Provide the researcher with an attendance list at all activities held by the facility for the intervention period only. This would include the time directly after the first interviews to the time in which the second interviews have been completed. 
Project:

\section{Control Group Proposal \\ Appendix G}

4. The focus of the project is on depression in the elderly, particularly those elderly living in a nursing home facility.

5. I am looking at types of intervention aside from drug therapy and psychotherapy to reduce symptoms of depression .

6. Morris Memorial has been nonrandomly chosen as a control match to participate in the study. The facility will have the option to accept or decline study in their facility.

\section{What the Project Will Include:}

4. Two interviews will be done by Shannon Lawson and two other CHPR graduate students with a sample of residents in the facility. These interviews will be in a questionnaire format.

5. The time between the first and second interview will be approximately four weeks. The content of the second interview will be the same as the first with the exception of a few questions.

6. Intervention: The facility has the option to participate in a delayed intervention after posttest has been completed. Volunteers from a local church have agreed to lead gospel singing in the facility one hour a week for four weeks upon agreement with the facility.

\section{*All information collected during interviews will be kept confidential as noted in the consent form.}

\section{$\underline{\text { Responsibilities of the Researcher }}$}

4. The researcher will conduct all interviews with the residents.

5. The researcher will coordinate all volunteers and visits with the residents.

6. The researcher will provide the staff, residents, and their families (who are interested) with a copy of the findings after the study is complete and data has been analyzed. 


\section{What is Asked of the Facility}

4. Assist the interviewers in identifying those residents who are able (physically and mentally) to be interviewed.

5. The use of the facility for visits from the church group (if accepted). 


\section{References}

Abrams, R.C., Teresi, J.A. \& Butin, D.N. (1992). Depression in nursing home residents. Clinics in Geriatric Medicine, 8, 309-321.

Administration on Aging. (1998). Profile of Older Americans [on-line]. www.aoa.dhhs.gov/

Administration on Aging. (1998). Profile of West Virginia [on line]. www.aoa.dhhs.gov/aoa/hcbltc/profiles/WestVirginia/html.

Ames, D. (1993). Depressive disorders among elderly people in long-term institutional care. Australian and New Zealand Journal of Psychiatry, 27, 379391.

Berkman, L.F. (1985). Cohn, S.\& Syme, S. (Eds.). (1997). The relationship of social networks and social support to morbidity and mortality. Social Support and Health. New York, Academic Press.

Burns, B.J., Wagner, H.R., Taube, J.E., Magaziner, J., Prmutt, T. \& Landerman, L.R. (1993). Mental health service use by the elderly in nursing homes. American Journal of Public Health, 83, 331-337.

Butler, R.N. \& Lewis, M.I. (1995). Late-life depression: When and how to intervene. Geriatrics, 50 (8), 44-50.

Butler, R.N. (1997). Depression in the primary care practice. Geriatrics, 25 (3), 7-9.

Fick, K. (1993). The influence of an animal on social interactions of nursing home residents in a group setting. American Journal of Occupational Therapy, 47, 529534.

Heaney, C.A. \& Israel, B.A. (1997). Social Support and Social Networks. In Glanz, K., Lewis, F.M., Rimer, B.K. (Eds.). Health Behavior and Health Education (p. 179201). San Francisco, CA: Jossey-Bass, Inc.

Kessler, R.C., McLeod, J.D., Cohen, S. \& Syme, S.L. (Eds). (1985). Social Support and Health. New York: Academic Press.

Lanza, A.F. \& Revenson, T.A. (1993). Social support interventions for rheumatoid arthritis patients: The cart before the horse?. Health Education Quarterly, 20 (1), 97-117. 
National Institute of Health. (1991). National Institute of Health Consensus Statement: Diagnosis and Treatment of Depression in Late Life [online]. Nov 4-6:9(3):1-27. http://odp.od.nih.gov

Prince, M.J., Harwood, R.H., Blizard, R.A., Thomas, A. \& Mann, A.H. (1997). Social support deficits, loneliness, and life events as risk factors for depression in old age: The Gospel Oak project VI. Psychological Medicine, 27, 323-332.

Puotinen, C.J. (1996). Pets are magic. Health News Naturally, 8, 4-9.

Radloff, L.S. (1997). The CES-D scale: A self-report depression scale for research in the general population. Applied Psychological Measures, 1, 385-401.

Radloff, L.S., \& Teri, L. (1986). Use of the center for epidemiological studies-depression scale with older adults. In Brink, T.L.(Ed.). Clinical Gerontology: A Guide to Assessment and Intervention (p. 119-134). The Haworth Press.

Reynolds, C.F. III. (1994). Treatment of depression in late life. The American Journal of Medicine, 97, 39-45.

Richardson, J.P. (1992). Health promotion for the nursing home patient. Journal of the American Board of Family Practice, 127-136.

Steuart, G. (1993). Social and behavioral change strategies. Health Education Quarterly,

Supplement 1: s113-s135.

Winkler, A., Fairnie, H., Gericevich, F. \& Long, M. (1989). The impact of a resident dog on an institution for the elderly: On perceptions and social interactions. Gerontologist, 29, 216-223. 